\title{
Modernization of the Target Design for Molybdenum Production
}

\section{Yu. Kolmykov, A. S. Zevyakin, R. V. Fomin, and A. V. Sobolev}

Department of Nuclear Physics and Technology, Obninsk Institute for Nuclear Power Engineering of the National Research Nuclear University MEPhl, Studgorodok 1, Obninsk, Kaluga region, 249040, Russia

\section{Annotation}

The following work is a comparative analysis of two target designs for Molybdenum99 production. Important parameters for their usage are their thermal-hydraulic properties. The considered target designs can be used in a research reactor of basin type. The research channel, where the target is being installed, does not possess high static pressure; therefore, the target should not cause the coolant boiling during operation. The more fissile material in the target, the higher the expected isotope producing and at the same time the energy release. The main task of construction

Corresponding Author:

A. S. Zevyakin

ASZevyakin@mephi.ru

Received: 23 December 2017

Accepted: 15 January 2018

Published: 21 February 2018

Publishing services provided by Knowledge $\mathrm{E}$

(c) V. Yu. Kolmykov et al. This article is distributed under the terms of the Creative Commons Attribution License, which permits unrestricted use and redistribution provided that the original author and source are credited.

Selection and Peer-review under the responsibility of the AtomFuture Conference Committee.

\section{G OPEN ACCESS} modernization of the target is to increase the production of the necessary radioisotope in the normal removal of heat from the walls of the target sleeve. Comparative analysis is carried out for targets of the cylindrical type.

Keywords: coolant temperature, energy release, target, heat exchange

\section{Introduction}

Today development of nuclear medicine is mostly associated with radionuclide diagnostics and treatment of oncological diseases. That is why increasing the production of radionuclide for medical purposes ${ }^{99} \mathrm{Mo}$ is an important goal. Molybdenum-99 is the element, by which about $70 \%$ of diagnostic procedures are carried out in the field of oncology, 50\% - in cardiology and about 90\% - in radionuclide diagnostics. Due to its difficulty and high cost of its production, it is widely available only in a few developed countries. Actually, Molybdenum-99 is not a final product that is used in nuclear medicine. There is another radioactive metal for such purpose - Technetium99.

Implementation of Molybdenum-99 production mainly depends on the design of the targets located in the technological channels of the reactor core. The efficiency of the production depends on a large extent of features of the target itself and the ways of its placement in the experimental channels. Therefore, an important part of 
the work is investigation of the various conditions that can be created for the target, what will possibly increase the production of Molybdenum-99 [1].

\section{Materials and methods}

The calculations were performed with using of finite element method by program complex ANSYS CFX.

Finite volume method (FVM) is a special case of the finite element method and it is designed for solving the problems described by partial differential equations with the given boundary conditions. FVM is fully justified theoretically and applies for solving a wide range of problems, such as:

- stationary problems of heat transfer, diffusion, electric field distribution and other problems of field theory;

- problems of hydrodynamics, fluid flow in a porous medium in particular;

- problems of mechanics and strength, including the design of aircraft, missiles, various spatial shields, etc. [2].

The basis of the method is the breakdown of the continuous domain of the definition of solving problem that has complex geometry. The initial area of the task definition is divided into sub-areas (or elements). These areas are interconnected at nodes. A solution, approximated by function of form element is sought on each element. An approximate solution is based on boundary conditions and a given mathematical formulation (system of equations).

The main advantages of the finite volume method are:

- the dimensions of the elements can be variable, what allows to enlarge or grind the mesh field and the elements, if necessary;

- the imposition of boundary conditions of various kinds and their combinations with the help of FVM, including local boundary conditions and/or mixed boundary conditions is not difficult [2].

The designed models consist of two targets, which are located in the channel. The vertical section of the targets is shown in Figure 1. On the left there is the image of the target that has already been in use, while on the right there is a new, modernized target of cylindrical type. The materials of both targets, including the filling of fissile material, are the same.

Materials, used for calculations and their main thermo-physical properties: 


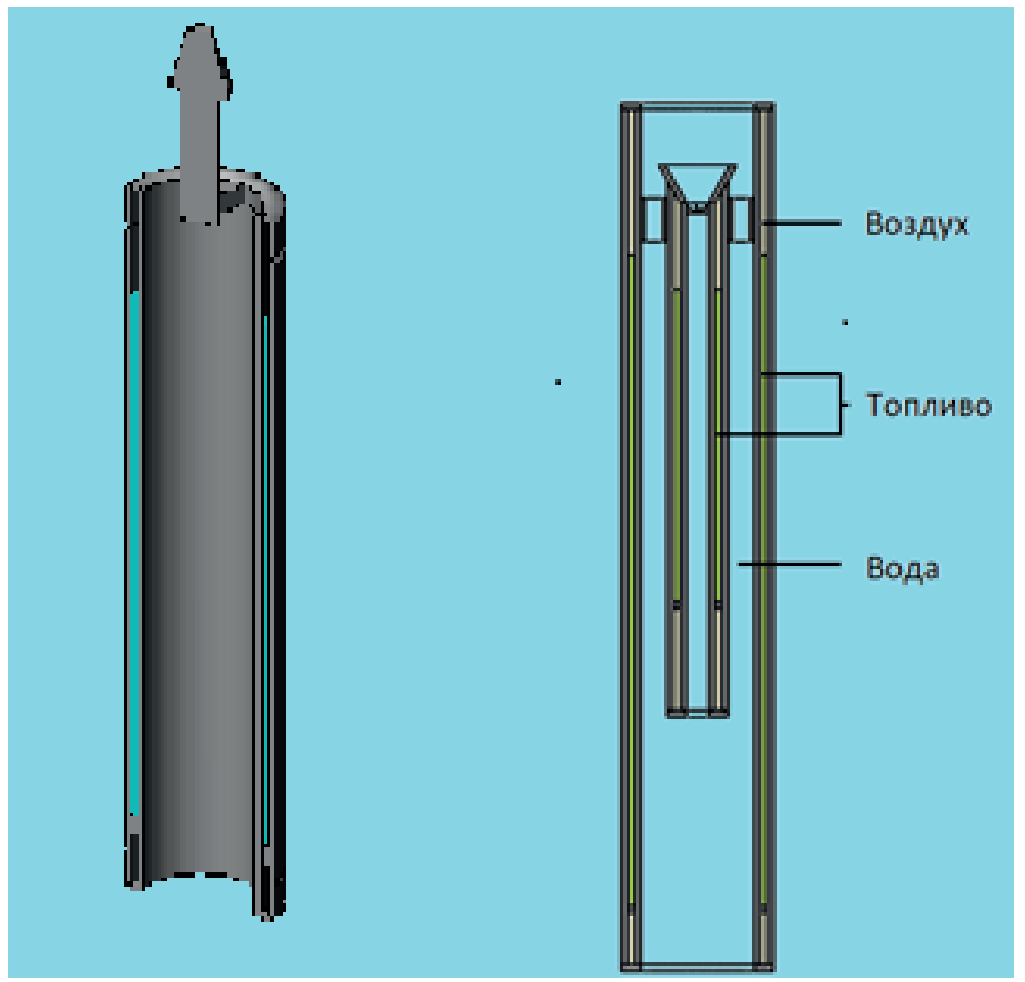

Figure 1: Vertical section of the target model.

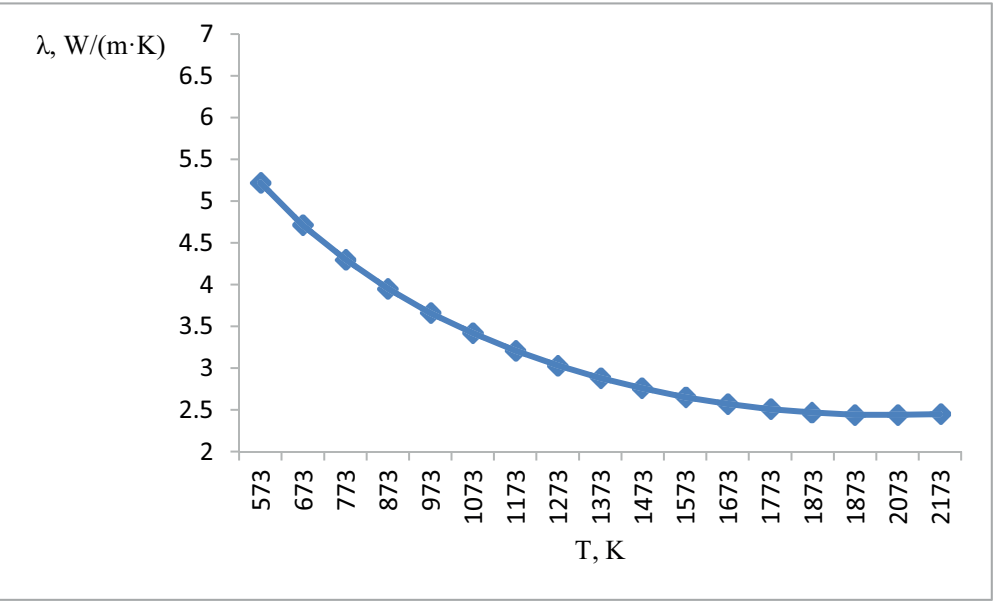

Figure 2: Dependence of the thermal conductivity of uranium dioxide on temperature.

TABLE 1: Comparison of the temperature characteristics of targets.

Total energy release, $\mathrm{kW}$
Average outlet temperature of the
coolant, ${ }^{\circ} \mathrm{C}$
Maximum temperature of the
coolant, ${ }^{\circ} \mathrm{C}$

The operating target The modernized target

\begin{tabular}{|c|c|}
\hline 50,2 & 46,1 \\
\hline 71,8 & 70,7 \\
\hline 96,3 & 91,8 \\
\hline
\end{tabular}




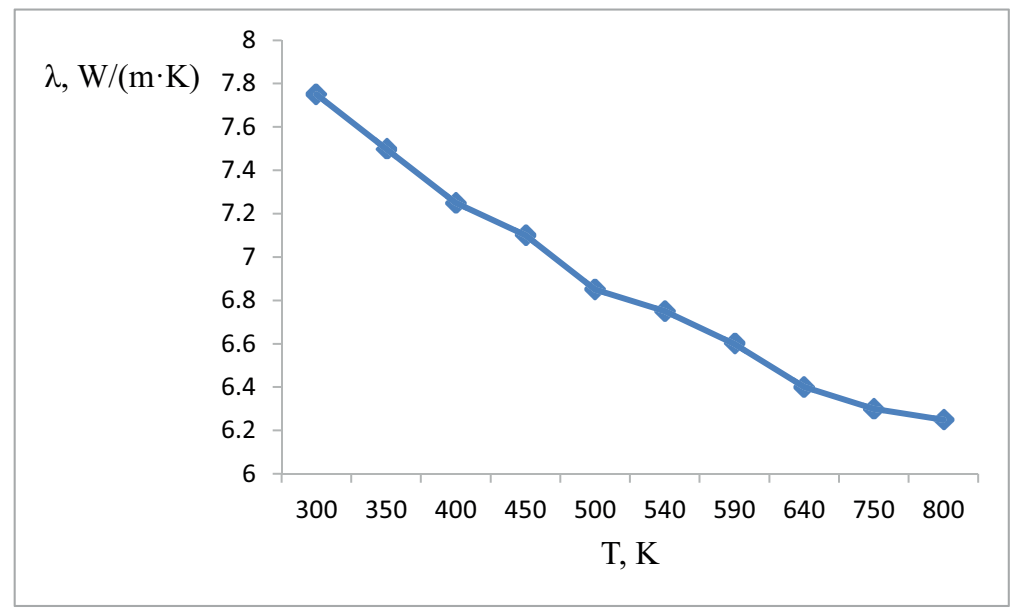

Figure 3: Dependence of the thermal conductivity of zinc oxide on temperature.

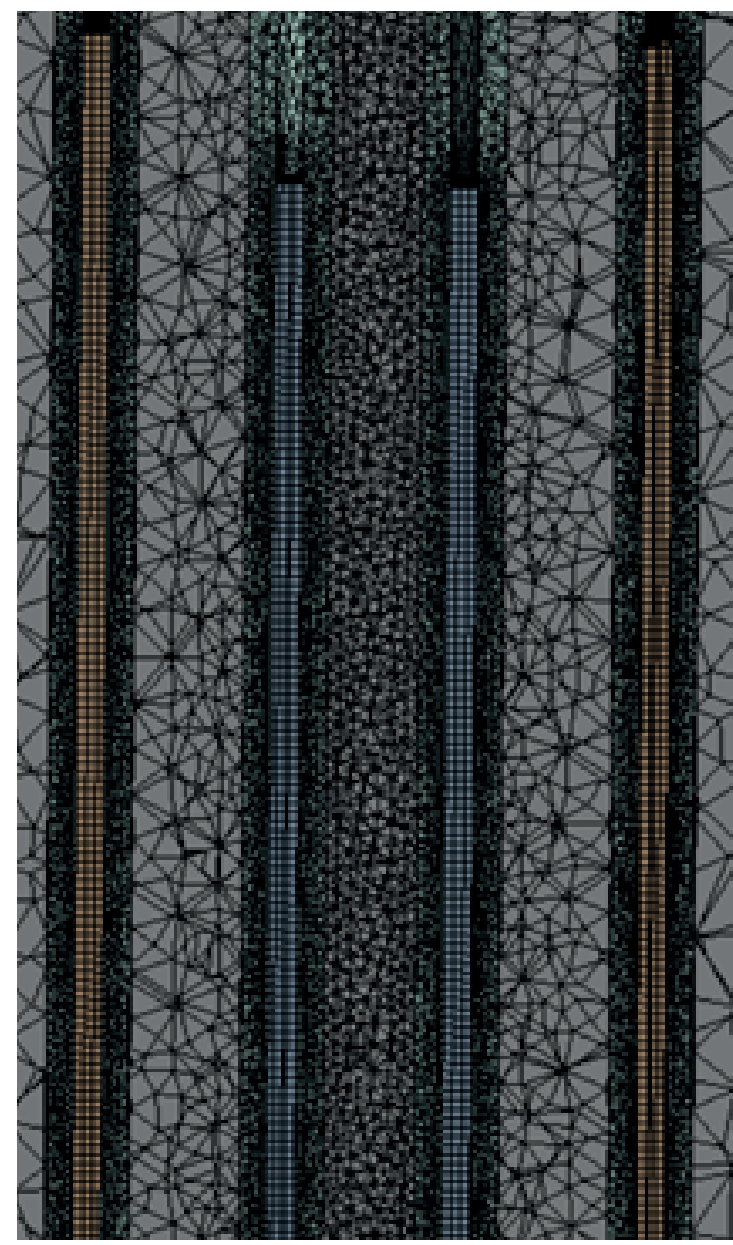

Figure 4: Layered mesh structure.

- Aluminum alloy:

- thermal conductivity $140 \mathrm{~W} /(\mathrm{m} \cdot \mathrm{K})$;

- density $2680 \mathrm{~kg} / \mathrm{m}^{3}$. 


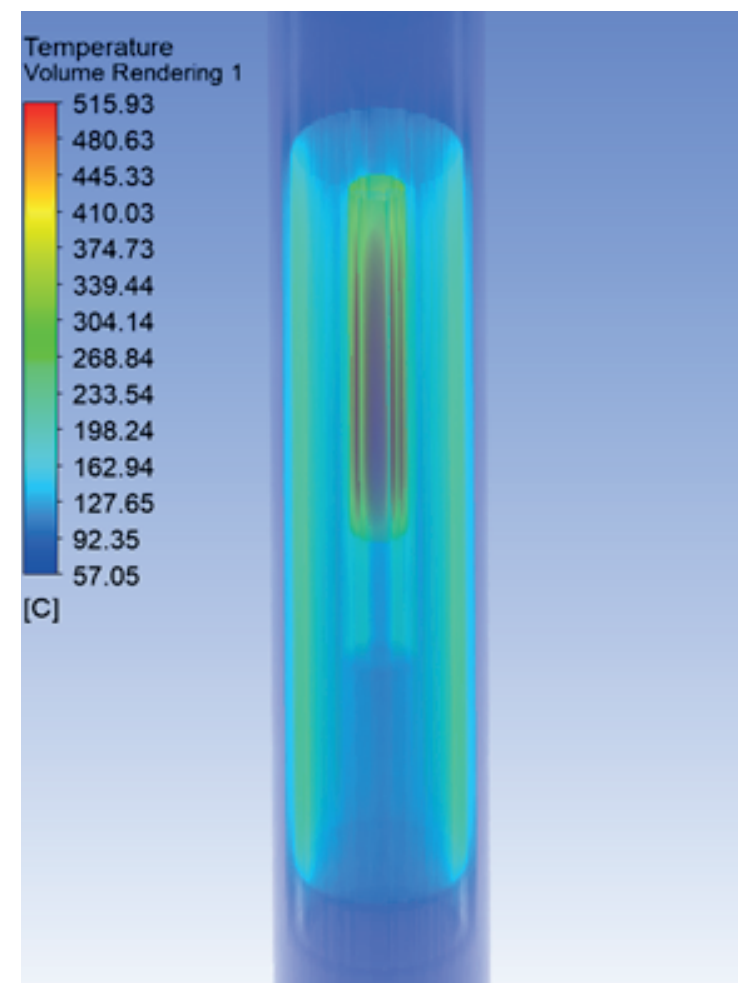

Figure 5: Temperature distribution of the lower target in the channel.

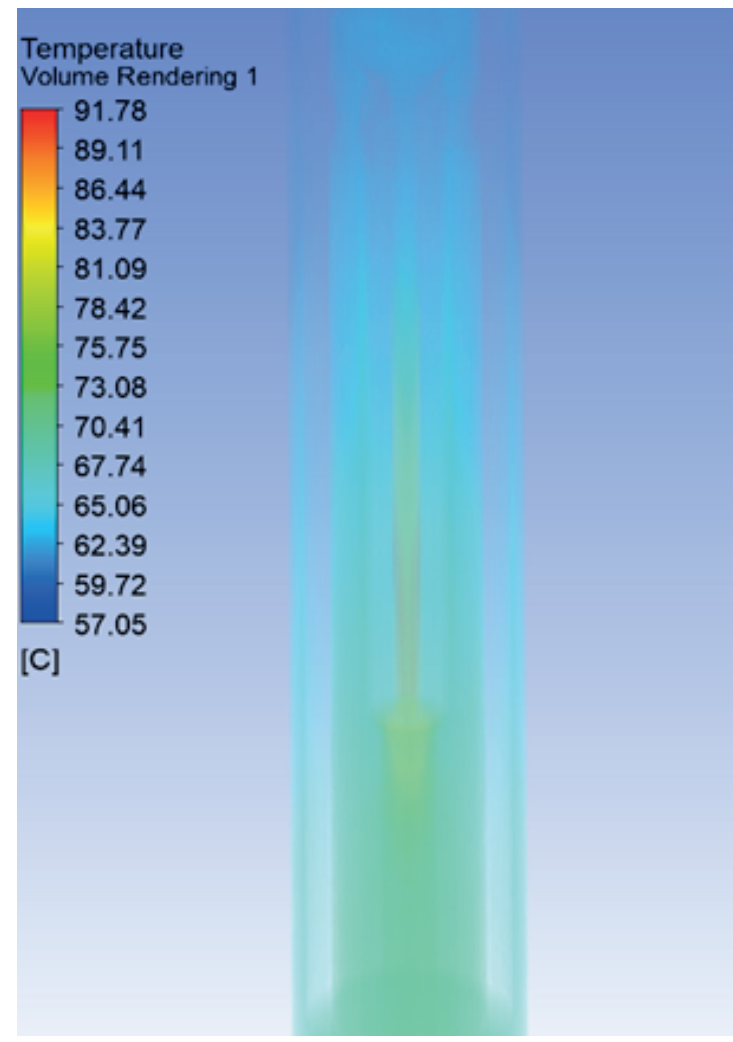

Figure 6: Temperature distribution of the coolant.

- Fissile material powder: 


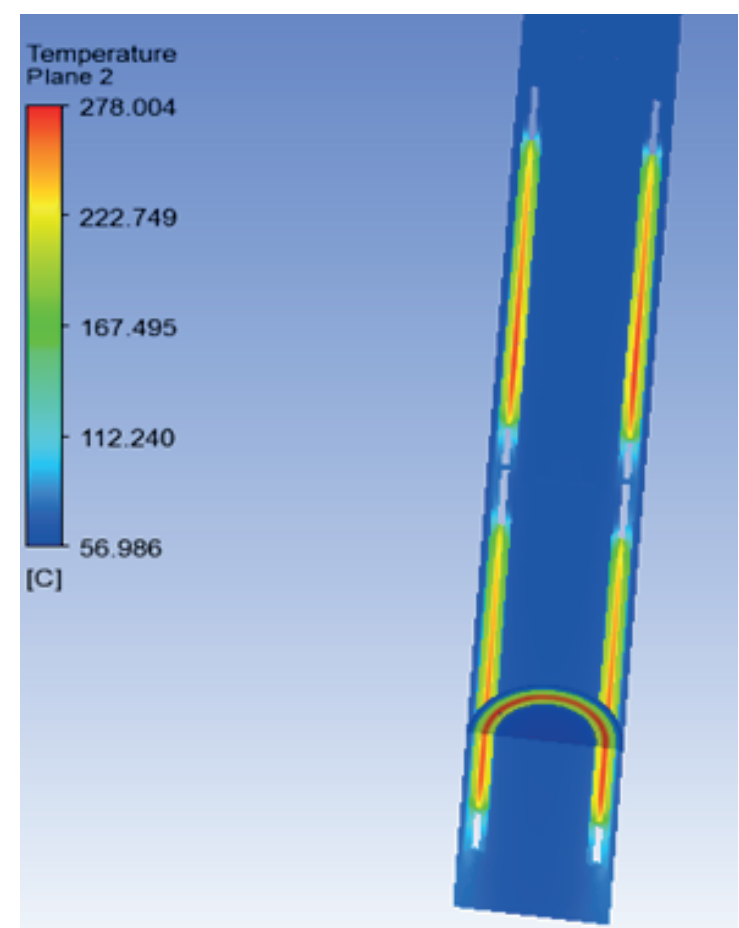

Figure 7: Temperature distribution by targets and coolant.

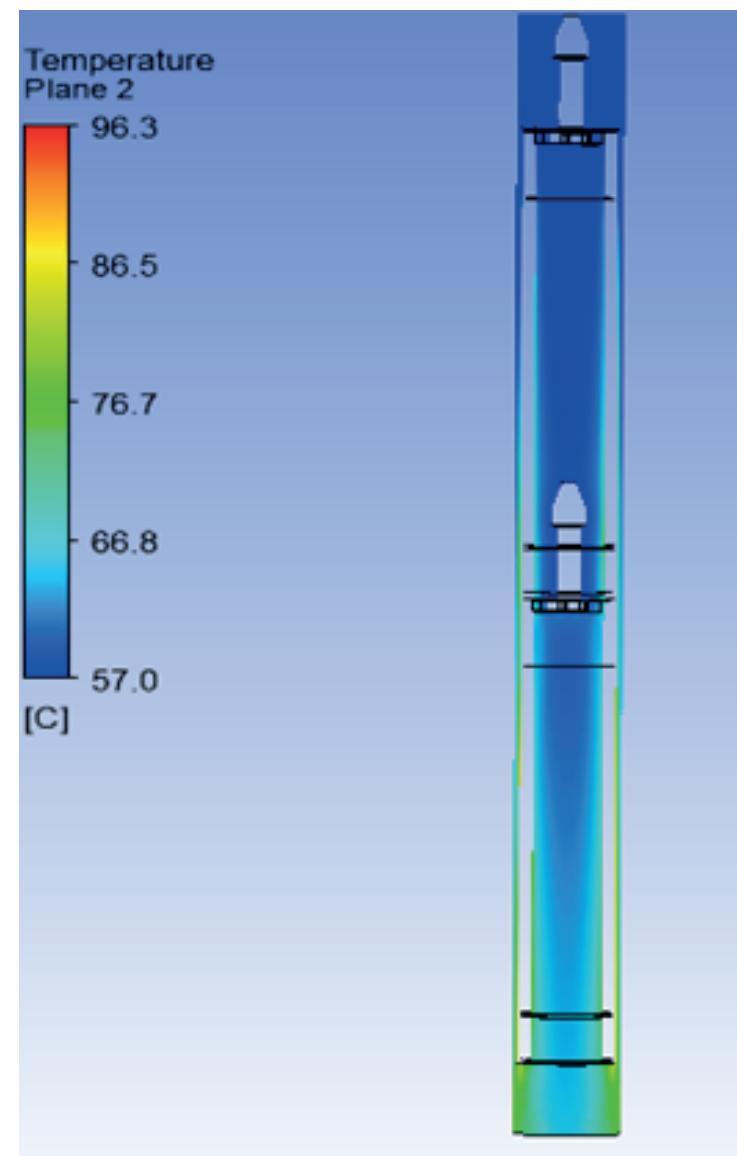

Figure 8: Temperature distribution by the coolant. 
- thermal conductivity 10,2 W/(m.K);

- density $4000 \mathrm{~kg} / \mathrm{m}^{3}$;

- Fluid (water):

- mass flow rate $0,82 \mathrm{~kg} / \mathrm{s}$;

- inlet temperature $57^{\circ} \mathrm{C}$;

- static pressure 171325 Pa [3].

The fissile material powder is a homogenous friable mixture of uranium dioxide and zinc oxide. Dependences of thermal conductivity of the fuel matrix components on temperature are taken in account when specifying the materials of the calculation model and are presented in Figures 2-3.

Energy release in the targets was found by the results of neutron-physical calculation performed by using of calculation code realizing the Monte Carlo method. For both cases, the energy release was given according to the volume of the fissile powder. For the new, modernized target, the values of energy release for fuel units are given below:

- for the lower target from the outer fuel layer $-8,35 \cdot 10^{8} \mathrm{~W} / \mathrm{m}^{3}$;

- for the upper target from the outer fuel layer $-8,16 \cdot 10^{8} \mathrm{~W} / \mathrm{m}^{3}$;

- for the lower target from the inner fuel layer $-1,68 \cdot 10^{9} \mathrm{~W} / \mathrm{m}^{3}$;

- for the upper target from the inner fuel layer $-1,58 \cdot 10^{9} \mathrm{~W} / \mathrm{m}^{3}$.

For the used target, the energy release is:

- for the lower target $-8,27 \cdot 10^{8} \mathrm{~W} / \mathrm{m}^{3}$;

- for the upper target $-8,75 \cdot 10^{8} \mathrm{~W} / \mathrm{m}^{3}[4,5]$.

To calculate the temperature fields of the targets and the temperature of the coolant in the channel, a "layered mesh" was used. This mesh is a layered structure on the side of the target walls, and in the rest, it is a mesh, built in the automatic mode of the WorkBench window of the ANSYS software package [6]. Figure 4 shows the layered mesh structure of the calculated model of a new, modernized target for the Molybdenum-99 production.

\section{Results}

In the Figures 5 and 6 there are the calculation results of temperature distribution on fuel matrices of the targets in the channel, on the coolant and metal sleeves. One of the 
main criteria that characterizes the parameters of the designed target is the maximum temperature of the coolant and the average outlet temperature of the coolant from the research channel. The results are given for the most energy-intensive location of the calculation model (lower target).

Figures 7 and 8 show the temperature distributions in the vertical section along the fuel matrices of the targets in the channel, the coolant and the metal sleeves.

According to the results of calculations of the modernized target, maximum of the temperature is on the inner layer of the lower target fuel and is equal to $516{ }^{\circ} \mathrm{C}$. The maximum of water temperature is on a thin wall layer and is $91,8{ }^{\circ} \mathrm{C}$, the maximum temperature of the target sleeve is localized on its inner surface on the fuel side and is equal to $409^{\circ} \mathrm{C}$.

Water heating that is carried out in the research channel can be estimated by using the formula [7]:

$$
N=G \cdot C p \cdot \Delta T,
$$

where $N$ - power $(\mathrm{kW}), G$ - mass flow rate of the coolant $0,82(\mathrm{~kg} / \mathrm{s}), \Delta T$ - heating of the coolant $\left({ }^{\circ} \mathrm{C}\right), C_{p}$ - heat capacity $4200 \mathrm{~J} /\left(\mathrm{kg} \cdot{ }^{\circ} \mathrm{C}\right)$. Thermal power released in the channel:

- the upper target - 22,7 kW;

- the lower target - 23,4 kW.

$$
\Delta T=\frac{N}{G \cdot C p}=13,4^{\circ} \mathrm{C}
$$

Knowing the inlet temperature of the coolant $\left(57^{\circ} \mathrm{C}\right)$, the outlet temperature of the water can be found:

$$
\begin{gathered}
\Delta T=T_{\text {out }}-T_{\text {in }} \\
T_{\text {out }}=70,4^{\circ} \mathrm{C}
\end{gathered}
$$

The average outlet temperature of the coolant, calculated in the ANSYS software complex is $70,7^{\circ} \mathrm{C}$.

For the case with the operating target, the water heating was evaluated by the same method. The data are given in [6].

\section{Discussion}

As it is seen in the results of the work presented in Table 1, the total energy release in the fuel matrix of the modernized target decreased by $4,1 \mathrm{~kW}$. It has happened due 
to the refinement of the fuel layer in comparison with the operating target. At the same time the maximum temperature of the coolant was decreased by $4,5^{\circ} \mathrm{C}$. Also, to increase the heat transfer intensity, an annular heat exchange intensifier was installed in the upper part of the target in a pair with a nozzle insert. The annular turbulator not only serves as a mixing device, but also used for fixing the inner cilynder to the outer part of the target. The nozzle insert allows to increase the velocity of the coolant flow in the central cylinder.

The average temperature at the outlet of the channel almost did not change. Engineering verification of the calculations by the formula for finding the coolant heating showed similar results to thermal-hydraulic calculation performed by the finite element method.

Considering the presence of static pressure in the channel, which is $171325 \mathrm{~Pa}$, as well as hydrostatic pressure of the liquid column above the target, it can be stated that there is no boiling of the coolant with the significant reserve until it. This fact allows to increase the thickness of the fuel layer in both the inner and outer cylinders of the modernized target, which in turn will lead to an increase in the producing of Molybdenum-99. The thickness of the fuel layer in the cylinder is determined by the results of a neutron-physical calculation that allows for the self-shielding effect to be taken and minimized.

The fuel temperature of the new, modernized target is higher than of the operating one, while the melting temperature of the fuel matrix is much higher than the calculated values, that is, the fuel does not melt.

\section{Conclusion}

A comparative analysis of the calculation results of thermal-hydraulic characteristics of two cylindrical-type targets shows the better parameters for the proposed target design in comparison with the operating one. The calculations showed a decrease in the maximum temperatures of the coolant, which makes it possible to increase the production of Molybdenum-99, by increasing the fuel material loading.

\section{References}

[1] R.V. Fomin, V.V. Kolesov, A.S. Zevyakin, O.Yu. Kovhnov. Estimation of ${ }^{99} \mathrm{Mo}$ production increase when using targets of modernized design at the VVR-TS reactor. Innovative nuclear reactors of small and ultra-small power. II International 
Conference of Young Schientists, Specialists, Postgraduates, Students: abstracts (Obninsk: May 15-17, 2017) - Obninsk: INPE NRNU MEPhl, 2017. - 54 P.

[2] V.A. Bruyaka, V.G. Fokin, E.A. Soldusova, N.A. Glazunova, I.E. Adeyanov. Бруяка В.А., Фокин В.Г., Солдусова Е.А., Глазунова Н.А., Адеянов И.Е. В 89 Engineering analysis in ANSYS Workbench: Proc. Help. / Samara: Samara St. Tech. University, 2010. -217 P.

[3] Technical report "Calculation of thermos-technical parameters of the experimental channel of the VVR-TS nuclear reactor for irradiating a flow-through block-container with uranium-containing material". Obninsk-2014.

[4] V.V. Kolesov, O.Yu. Kochnov, R.V. Fomin, Yu.V. Volkov, V.F. Ukraintsev. Creation of a precision model of the VVR-TS reactor for the subsequent optimization of its design and the production of ${ }^{99} \mathrm{Mo}$ and other radionuclides. Nuclear Power Engineering, Izv. Vuzov, №4, 2011, p.129-134.

[5] R.V. Fomin, V.V. Kolesov, O.Yu. Kochnov. Modernization of the VVR-TS reactor core for the increasing of the radionuclides production. IOP Conf. Series: Journal of Physics: Conf. Series Volume 781, Number 1 (012031).

[6] R.V. Fomin, A.S. Zevyakin, V.V. Kolesov, A.V. Sobolev, O.Yu. Kochnov. Modernization of targets for the production of molybdenum. Innovations in nuclear energy: Sat. reports of the conference of young specialists (May 23-24, 2017, Moscow). Moscow: Publishing house of JSC "NIKIET", 2017. 1098 p.

[7] P.L. Kirillov, Yu.S. Yuriev, V.P. Bobkov. Handbook of thermohydraulic calculations (nuclear reactors, heat exchangers, steam generators). - Moscow: Energoatomizdat, 1990. 